\title{
OPEN Genetic deletion of Abcc6 disturbs cholesterol homeostasis in mice
}

\author{
Bettina Ibold ${ }^{1}$, Janina Tiemann ${ }^{1}$, Isabel Faust ${ }^{1}$, Uta Ceglarek ${ }^{2}$, Julia Dittrich ${ }^{2}$, \\ Theo G. M. F. Gorgels ${ }^{3,4}$, Arthur A. B. Bergen ${ }^{4,5}$, Olivier Vanakker ${ }^{6}$, Matthias Van Gils ${ }^{6}$, \\ Cornelius Knabbe ${ }^{1} \&$ Doris Hendig ${ }^{1 凶}$
}

Genetic studies link adenosine triphosphate-binding cassette transporter C6 (ABCC6) mutations to pseudoxanthoma elasticum (PXE). $A B C C 6$ sequence variations are correlated with altered $\mathrm{HDL}$ cholesterol levels and an elevated risk of coronary artery diseases. However, the role of ABCC6 in cholesterol homeostasis is not widely known. Here, we report reduced serum cholesterol and phytosterol levels in Abcc6-deficient mice, indicating an impaired sterol absorption. Ratios of cholesterol precursors to cholesterol were increased, confirmed by upregulation of hepatic 3-hydroxy-3-methylglutaryl coenzyme A reductase ( $\mathrm{Hmgcr}$ ) expression, suggesting activation of cholesterol biosynthesis in $\mathrm{Abcc6}^{-/-}$mice. We found that cholesterol depletion was accompanied by a substantial decrease in HDL cholesterol mediated by lowered ApoA-I and ApoA-II protein levels and not by inhibited lecithin-cholesterol transferase activity. Additionally, higher proprotein convertase subtilisin/kexin type 9 (Pcsk9) serum levels in $\mathrm{Abcc6}^{-/-}$mice and PXE patients and elevated ApoB level in knockout mice were observed, suggesting a potentially altered very low-density lipoprotein synthesis. Our results underline the role of Abcc6 in cholesterol homeostasis and indicate impaired cholesterol metabolism as an important pathomechanism involved in PXE manifestation.

Mutations in the adenosine triphosphate-binding cassette transporter C6 (ABCC6) gene are responsible for pseudoxanthoma elasticum (PXE), a metabolic disease, hallmarked by a progressive elastic fiber calcification of the skin, eyes and cardiovascular system. Yellowish papules of the neck and flexure areas are often the first clinical signs of PXE, which were wrongly considered as xanthomas in early research ${ }^{1}$. Characteristic xanthomas are lesions in connective tissue formed by lipid-overloaded macrophages ${ }^{2}$. By contrast, skin lesions of PXE are due to morphological alterations of elastin fibers.

Recent studies verified that ABCC6 is involved in systemic pyrophosphate homeostasis although the physiological function and substrates of ABCC6 remain unknown/can be only presumed ${ }^{3,4}$. However, an in silico analysis from Hosen et al. showed that lipids and bile acids are particularly the most likely ABCC6 substrates ${ }^{5}$. Several ABCC6 sequence variations correlate with altered HDL cholesterol, triglyceride levels ${ }^{6}$, and an increased coronary risk ${ }^{7}$. A previous study demonstrated decreased HDL cholesterol plasma levels in 8-month-old $A b c c 6^{-1-}$ mice ${ }^{8,9}$. Furthermore, Guo et al. showed that a preventive treatment with atorvastatin inhibited calcifications in $\mathrm{Abcc6}^{-1-}$ mice ${ }^{9}$. However, the underlying mechanism why inhibition of 3-hydroxy-3-methylglutaryl coenzyme A reductase (HMGCR) can suppress ectopic mineralization is not clear ${ }^{10}$. Previously, we investigated cholesterol biosynthesis in dermal fibroblasts of PXE patients and observed increased HMGCR activity in comparison to healthy controls. Moreover, we showed increased proprotein convertase subtilisin/kexin type 9 (PCSK9) levels and altered ApoE expression ${ }^{11}$. Elastic fiber calcification observed in PXE is associated with decreased pyrophosphate levels in PXE patients and $A b c c 6^{-/-}$mice ${ }^{12,13}$. Thus, bisphosphonates as nonhydrolyzable pyrophosphate analogues are potential candidates for treatment of PXE in addition to statins ${ }^{13,14}$. Bisphosphonates containing nitrogen inhibit alkaline phosphatase directly ${ }^{15}$, which degrades pyrophosphate and, therefore, promotes the mineralization process ${ }^{3}$. Moreover, both statins and bisphosphonates inhibit enzymes involved in the cholesterol biosynthesis ${ }^{16}$. Cholesterol has an important structural and metabolic function. It is an essential cell membrane component, a starting molecule for steroid hormone synthesis and for the formation of cofactors,

\footnotetext{
${ }^{1}$ Institut für Laboratoriums- und Transfusionsmedizin, Herz- und Diabeteszentrum Nordrhein-Westfalen, Universitätsklinik der Ruhr-Universität Bochum, 32545 Bad Oeynhausen, Germany. ${ }^{2}$ Institut für Laboratoriumsmedizin, Klinische Chemie und Molekulare Diagnostik, Universitätsklinikum Leipzig, 04103 Leipzig, Germany. ${ }^{3}$ University Eye Clinic Maastricht, Maastricht University Medical Center, 6202 AZ Maastricht, The Netherlands. ${ }^{4}$ Netherlands Institute for Neurosciences (NIN-KNAW), Amsterdam, The Netherlands. ${ }^{5}$ Academic Medical Centre, University of Amsterdam, 1100 DD Amsterdam, The Netherlands. ${ }^{6}$ Center for Medical Genetics, Ghent University Hospital, 9000 Ghent, Belgium. ${ }^{\circledR}$ email: dhendig@hdz-nrw.de
} 
vitamins and bile acids. But high blood cholesterol levels can have pathological consequences, for example, the development of vascular diseases. In addition, excessive accumulation of cholesterol is cell toxic and should be prevented or reduced via reverse cholesterol transport. Only hepatocytes and hormone-producing cells can metabolize cholesterol ${ }^{17}$. Maintenance of cholesterol homeostasis is primarily ensured by hepatic mechanisms, such as cholesterol biosynthesis, receptor-mediated uptake of lipoproteins, lipoprotein secretion, cholesterol degradation and storage (summarized $\mathrm{in}^{18}$ ). However, cells of peripheral tissues are capable of activating cholesterol synthesis due to their metabolic needs ${ }^{19}$.

Here, we used 6- and 12-month old $A b c c 6^{-/-}$mice to reflect an early and a late disease stage of PXE to study the effects of an Abcc6 deficiency on cholesterol homeostasis. In this study, we found reduced HDL and total cholesterol levels in the serum of 12-month-old $A b c c 6^{-1-}$ mice. These $A b c c 6^{-1-}$ mice also showed consistently lower ApoA-I and ApoA-II levels and reduced phytosterol amounts in their serum. These results indicate that the ABC-transporter Abcc6 plays a relevant role in cholesterol metabolism and add new insights into the pathophysiology of PXE.

\section{Results}

Reduced serum lipid levels due to Abcc6 deficiency. In general no statistically significant differences were found between male and female mice. Free, esterified, and total serum cholesterol of 6-month-old $\mathrm{Abcc6}^{-/-}$ mice were not altered in comparison to WT mice. A significant decrease of esterified and total cholesterol is shown for 12-month-old $A b c c 6^{-/-}$mice (Fig. 1A). We observed no reduction of HDL cholesterol in the serum of 6-month-old $A b c c 6^{-1-}$ mice (Fig. 1B), whereas significantly decreased levels of esterified and total serum cholesterol in 12-month-old $A b c c 6^{-/-}$mice were attributed to a substantial decrease in HDL cholesterol $(-25 \%$; Fig. 1B). A reduction of oxidized LDL (oxLDL) was solely detected in the serum of 12-month-old $A b c c 6^{-/-}$mice (-17\%; Fig. 1C).

Comparing 6-month-old $\mathrm{Abcc6}^{-/-}$mice and WT mice, alterations in serum concentrations of the cholesterol precursors lanosterol and zymosterol/desmosterol/7-dehydrocholesterol (zy/de/7dhc) were insignificant. However, lanosterol levels in serum of 12 -month-old $\mathrm{Abcc6}^{-1-}$ mice were decreased by $38 \%$ (Fig. 1D). A significant reduction in the ratio of free lanosterol to cholesterol was found in 12-month-old $A b c c 6^{-/-}$mice. By contrast, the ratio of free $\mathrm{zy} / \mathrm{de} / 7 \mathrm{dhc}$ to total cholesterol was significantly increased in both groups of $A b c c 6^{-/-}$mice compared to WT mice (Table 1).

We quantified lower serum plant sterol levels overall (free, esterified and total brassicasterol, campesterol, $\beta$-sitosterol and stigmasterol) of both groups of $A b c c 6^{-1-}$ mice analyzed in comparison to WT mice (Fig. 2A-D). We detected significant reductions of both esterified campesterol (6-month-old: $-32 \%$; 12 -month-old: $-45 \%$ ) and total campesterol (6-month-old: -27\%; 12-month-old: - 41\%) of 6- and 12-month-old Abcc6 knockout mice (Fig. 2B). Esterified (6-month-old: $-30 \% ; 12$-month-old: $-40 \%)$ and total $\beta$-sitosterol (6-month-old: $-29 \%$; 12-month-old: - 39\%) were also significantly reduced in 6- and 12 -month-old $A b c c 6^{-1}$ mice (Fig. 2C). In addition, a significant reduction of free $(-41 \%)$, esterified $(-30 \%)$ and total brassicasterol $(-37 \%)$ was determined in the serum of 12 -month-old $A b c c 6^{-1-}$ mice (Fig. 2A). Decreased serum levels of esterified (-33\%) and total stigmasterol $(-32 \%)$ were also identified in 12 -month-old $A b c c 6^{-/-}$mice (Fig. 2D). Table 1 summarizes that ratios of all phytosterols to cholesterol quantified were lower in both age groups of $A b c c 6^{-1-}$ mice compared to WT mice. The ratios of brassicasterol $(-0.6 \mu \mathrm{g} / \mathrm{mg})$, campesterol $(-5.9 \mu \mathrm{g} / \mathrm{mg}), \beta$-sitosterol $(-1.9 \mu \mathrm{g} / \mathrm{mg})$, and stigmasterol $(-0.2 \mu \mathrm{g} / \mathrm{mg})$ to cholesterol were significantly reduced in 12 -month-old $A b c c 6^{-1-}$ mice (Table 1$)$.

Gene expression profile of key enzymes in cholesterol biosynthesis of liver tissue. Figure 3A shows that the relative mRNA expression of $\mathrm{Hmgcr}$ was moderately increased in 6-month-old (1.5-fold) and 12-month-old (1.3-fold) $A b c c 6^{-1-}$ mice compared to WT mice. The transcript level of Fdft1 was significantly downregulated by $30 \%$ in the liver tissue of 12 -month-old $A b c c 6^{-1-}$ mice, whereas younger $A b c c 6^{-/-}$mice showed a 1.8-fold increase in Fdft1 expression. Moreover, hepatic mRNA expression of Lss was significantly elevated up to 1.5 -fold in 6-month-old $A b c c 6^{-/-}$mice (Fig. $3 \mathrm{~A}$ ).

Gene expression and serum levels of apos in Abcc 6 deficiency. In comparison to WT mice, expression of Apoa 2 was significantly reduced in the liver samples of 6- and 12 -month old $A b c c 6^{-/-}$mice (Fig. 3B), while Apoe mRNA expression was 1.5-fold higher in the liver samples of 6-month old $A b c c 6^{-1-}$ mice. Furthermore, gene expression of Apoa1 showed a 1.4-fold increase and the transcript level of Apoc1 was 1.1-fold elevated in the liver tissue of 12-month old $A b c c 6^{-/-}$mice (Fig. 3B). ApoC-II and ApoC-III mRNA expression levels were not different between $A b c c 6^{-/-}$and WT (Suppl. Figure 1).

In addition to the gene expression analysis, we determined apo serum concentrations (Fig. 4A-D). The levels of ApoA-I were significantly decreased in both age classes of $A b c c 6^{-1-}$ mice compared to WT mice (6-month-old: $-18 \%$; 12 -month-old: $-18 \%$, Fig. 4A). An even stronger reduction of Apo-II serum levels was demonstrated in $A b c c 6^{-1-}$ mice (6-month-old: - 36\%; 12 -month-old: $-34 \%$, Fig. 4B). Twelve-month-old $A b c c 6^{-1-}$ mice also showed significantly lower ApoA-IV and ApoC-I levels ( $-12 \%$ and $-25 \%$, respectively, Fig. 4C,E). As opposed to these reductions, ApoB was significantly increased by $12 \%$ in both 6 - and 12 -month-old $A b c c 6^{-/-}$mice (Fig. 4D). ApoE serum concentrations were not different between $A b c c 6^{-1-}$ and WT mice (Fig. 4F).

Analysis of enzymes lipoprotein metabolizing in Abcc6-deficient mice. In comparison to WT mice, higher transcript levels of sterol o-acyltransferase 2 (Soat2) (1.6-fold) were found in the liver tissue of 6-month-old $A b c c 6^{-/-}$mice, whereas expression was repressed in older $A b c c 6^{-1-}$ mice (Fig. 5A). Furthermore, phospholipid transfer protein (Pltp) mRNA expression was reduced by $30 \%$ in the liver tissue of 12 -month-old $A b c c 6^{-/-}$mice. Phospholipase activity of Lcat was determined in a fluorometric assay in which lower signal 


\section{A serum cholesterol}

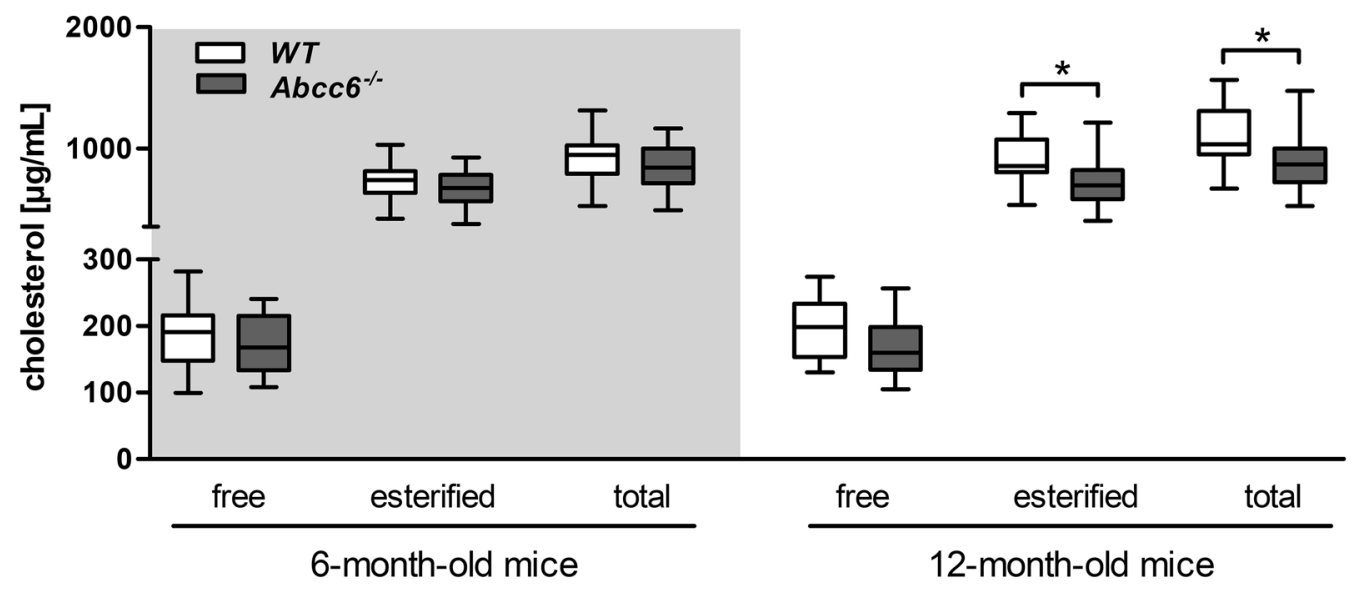

B HDL and LDL + VLDL cholesterol

C oxLDL cholesterol

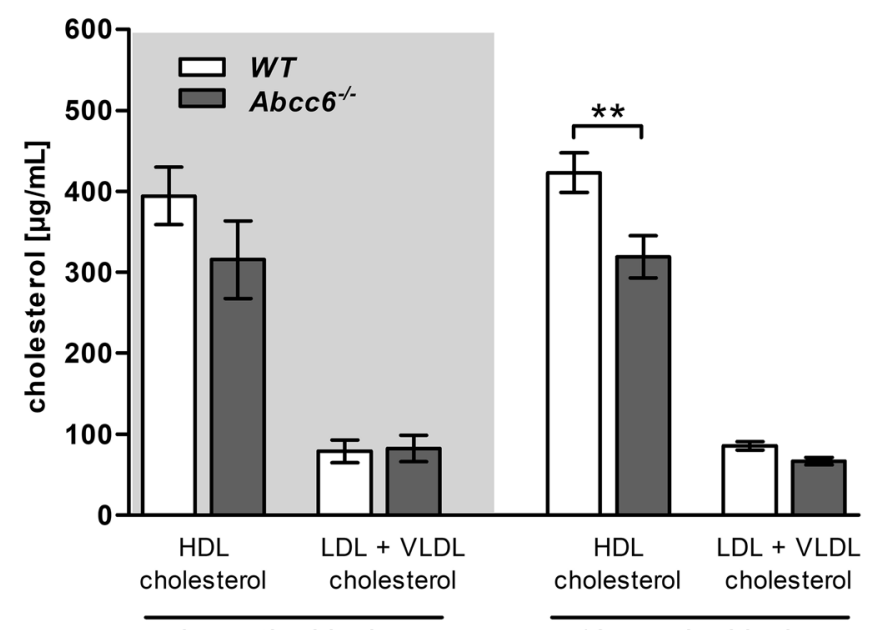

6-month-old mice

12-month-old mice

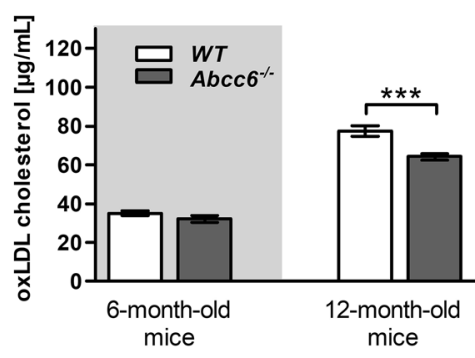

\section{D cholesterol precursors}

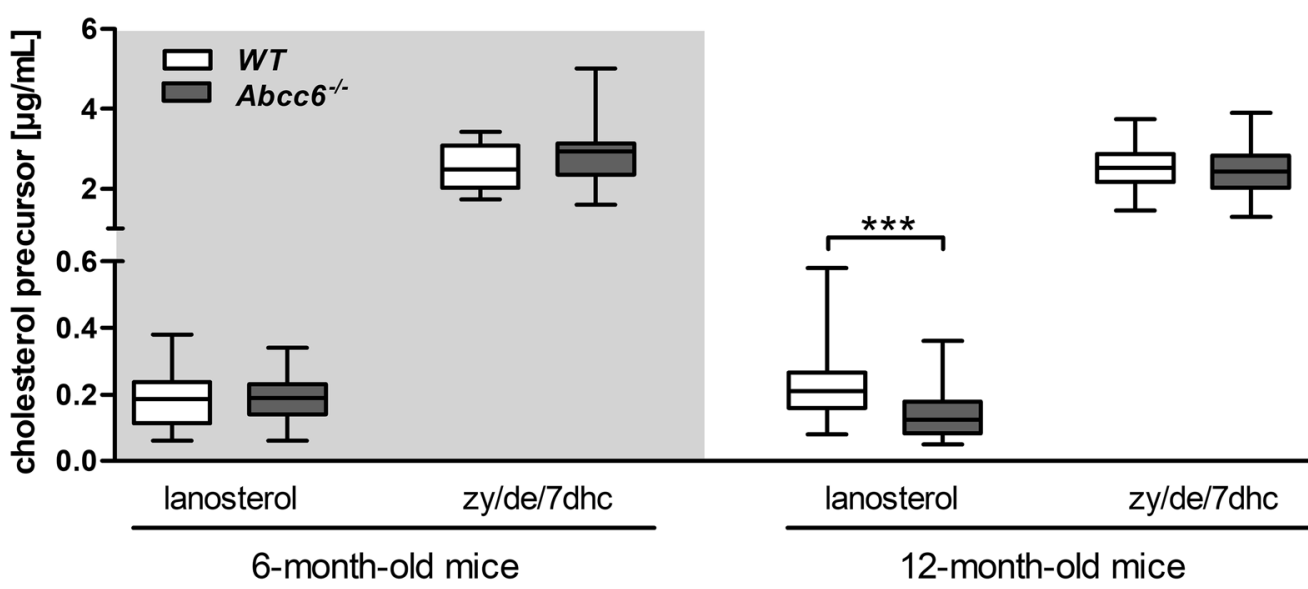

Figure 1. Reduced serum lipids in Abcc6 knockout mice. (A) Serum levels of free, esterified and total cholesterol of WT and $A b c c 6^{-/-}$mice (6-month-old: WT $\mathrm{n}=28, A b c c 6^{-/-} \mathrm{n}=19 ; 12$-month-old: WT $\mathrm{n}=41, A b c c 6^{-/-} \mathrm{n}=40$ ). (B) Serum levels of HDL and LDL + VLDL cholesterol of WT and $A b c c 6^{-/-}$mice (6-month-old: WT n $=8, A b c c 6^{-1-} \mathrm{n}=4$; 12-month-old: WT $\left.\mathrm{n}=18, A b c c 6^{-/-} \mathrm{n}=17\right)$. (C) Quantification of oxLDL cholesterol serum levels of WT and $A b c c 6^{-/-}$mice (6-month-old: WT $\mathrm{n}=23, A b c c 6^{-/-} \mathrm{n}=17 ; 12$-month-old: WT $\mathrm{n}=29, A b c c 6^{-/-} \mathrm{n}=29$ ). (D) Serum levels of free cholesterol precursors, lanosterol and zymosterol/desmosterol/7-dehydrocholesterol (zy/de/7dhc) of WT and $A b c c 6^{-/-}$mice (6-month-old: WT n $=28, A b c c 6^{-1-}$ $\mathrm{n}=19 ; 12$-month-old: WT $\left.\mathrm{n}=41, A b c c 6^{-/-} \mathrm{n}=40\right)$. Data are mean \pm SD; one factorial variance analysis $(\mathbf{A}, \mathbf{B}, \mathbf{D})$ or Student's $t$ test $(\mathbf{C}) ;{ }^{*} \mathrm{p} \leq 0.05 ;{ }^{* *} \mathrm{p} \leq 0.01 ;{ }^{* * *} \mathrm{p} \leq 0.001$. 


\begin{tabular}{|c|c|c|c|c|c|c|}
\hline \multirow[b]{2}{*}{ Ratio $(\mu \mathrm{g} / \mathrm{mg})$} & \multicolumn{3}{|c|}{ 6-month-old mice } & \multicolumn{3}{|c|}{ 12-month-old mice } \\
\hline & WT $(n=28)$ & $A b c c 6^{-/-}(\mathrm{n}=19)$ & p-value & WT $(n=41)$ & $A b c c 6^{-/-}(\mathrm{n}=40)$ & p-value \\
\hline Lanosterol $_{\text {free }}$ to cholesterol total $_{1}$ & $0.21 \pm 0.02$ & $0.24 \pm 0.02$ & 0.233 & $0.21 \pm 0.02$ & $0.16 \pm 0.01$ & $0.005^{* *}$ \\
\hline $\mathrm{zy} / \mathrm{de} / \mathrm{dh}_{\text {free }}$ to cholesterol $\mathrm{l}_{\text {total }}$ & $0.51 \pm 0.02$ & $0.62 \pm 0.03$ & $0.001^{* *}$ & $0.44 \pm 0.02$ & $0.53 \pm 0.02$ & $0.003^{* *}$ \\
\hline Brassicasterol $_{\text {total }}$ to cholesterol $\mathrm{l}_{\text {total }}$ & $0.51 \pm 0.02$ & $0.62 \pm 0.03$ & 0.361 & $0.44 \pm 0.02$ & $0.53 \pm 0.02$ & $0.003^{* \star}$ \\
\hline Campesterol $_{\text {total }}$ to cholesterol total $_{1}$ & $22.58 \pm 0.89$ & $18.42 \pm 2.14$ & 0.086 & $25.09 \pm 0.93$ & $19.18 \pm 1.20$ & $0.001^{* * *}$ \\
\hline$\beta$-Sitosterol ${ }_{\text {total }}$ to cholesterol ${ }_{\text {total }}$ & $8.84 \pm 0.32$ & $6.97 \pm 0.97$ & 0.109 & $8.89 \pm 0.33$ & $6.99 \pm 0.47$ & $0.002^{* *}$ \\
\hline Stigmasterol $_{\text {total }}$ to cholesterol ${ }_{\text {total }}$ & $0.95 \pm 0.03$ & $0.94 \pm 0.10$ & 0.863 & $1.11 \pm 0.05$ & $0.96 \pm 0.05$ & $0.038^{*}$ \\
\hline
\end{tabular}

Table 1. Elevated cholesterol precursor to cholesterol ratios and reduction of relative plant sterol levels in Abcc6 knockout mice. Ratios of free cholesterol precursors [lanosterol and zymosterol/desmosterol/7dehydrocholesterol (zy/de/7dhc)] and total phytosterols (brassicasterol, campesterol, $\beta$-sitosterol, stigmasterol) to total cholesterol $(\mu \mathrm{g} / \mathrm{mg} \pm \mathrm{SD})$ in serum of 6 - and 12 -month-old WT and Abcc6 ${ }^{-/-}$mice. Student's $t$ test; ${ }^{*} \mathrm{p} \leq 0.05 ;{ }^{* *} \mathrm{p} \leq 0.01 ;{ }^{* * *} \mathrm{p} \leq 0.001$.

A) brassicasterol

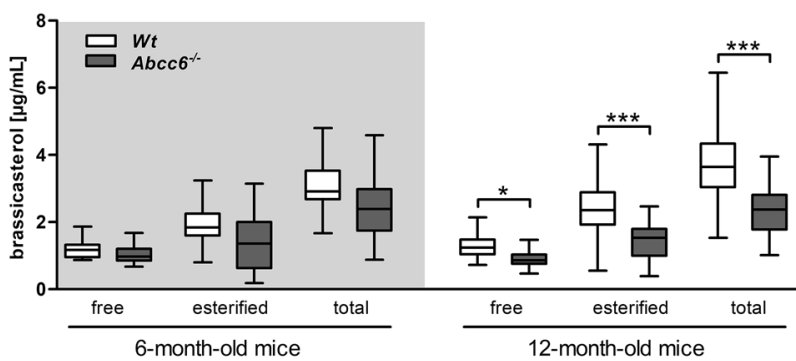

C) sitosterol

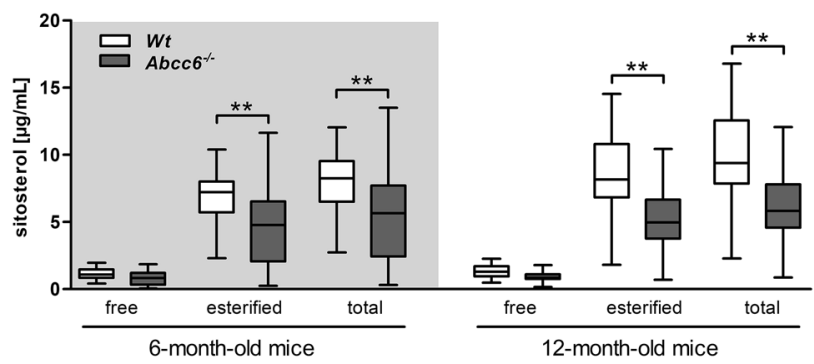

B) campesterol

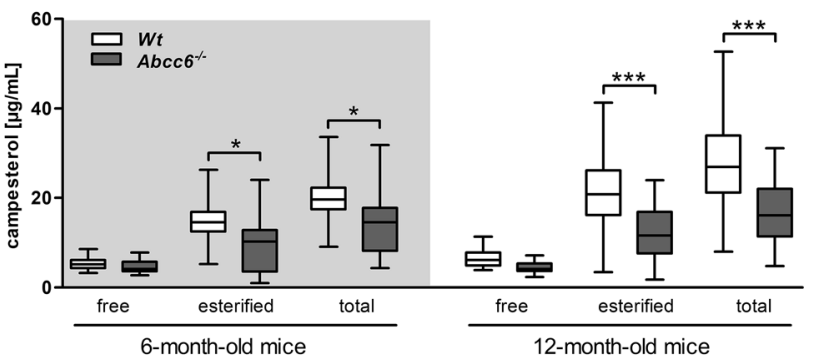

D) stigmasterol

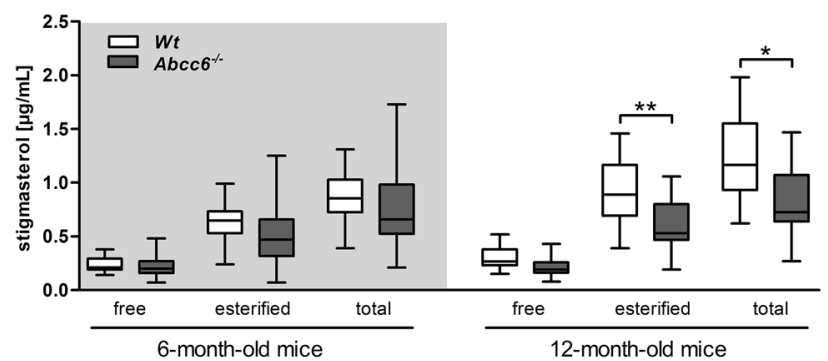

Figure 2. Reduced plant sterol levels in serum of Abcc6 knockout mice. Free, esterified and total phytosterol serum levels of WT and $A b c c 6^{-1-}$ mice (6-month-old: WT $\mathrm{n}=28, A b c c 6^{-/-} \mathrm{n}=19$; 12-month-old: WT $\mathrm{n}=41$, $A b c c 6^{-1-} \mathrm{n}=40$ ). (A) brassicasterol, (B) campesterol, (C) $\beta$-sitosterol and (D) stigmasterol. Data are mean $\pm \mathrm{SD}$; one factorial variance analysis; ${ }^{*} \mathrm{p} \leq 0.05 ;{ }^{* *} \mathrm{p} \leq 0.01 ;{ }^{* *} \mathrm{p} \leq 0.001$.

intensity corresponds to higher enzyme activity. Figure 5B show that Lcat activity was lower by $5 \%$ in 6 -monthold $\mathrm{Abcc6}^{-/-}$mice compared to WT mice. However, differences in older mice were insignificant.

We observed significantly higher $\mathrm{Lpl}$ gene expression in the liver tissue of 6-month-old $A b c c 6^{-1-}$ mice (2.5fold) than in WT mice. The expression of hepatic $L p l$ was also highly induced in 12 -month-old $A b c c 6^{-/-}$mice (3.4-fold; Fig. 5C). The extrahepatic expression level of $L p l$ was only significantly increased in the white adipose tissue of 6-month-old $A b c c 6^{-/-}$mice (1.4-fold). The transcript level of hepatic lipase (Lipc) was significantly upregulated in 6-month-old $A b c c 6^{-1-}$ mice (1.3-fold; Fig. 5D). In contrast to the elevated Lpl gene expression in $A b c c 6^{-1-}$ mice, no differences of protein expression were found in these mice (Fig. 5E).

Altered gene and protein expression of Pcsk9 and LDL receptor (Ldlr) in Abcc6-deficient mice. The expression of Pcsk9 and Ldlr in the liver tissue of Abcc6-deficient and WT mice was similar (Fig. 6A). By contrast, the relative mRNA expression of $L d l r$ in the white adipose tissue of 6-month-old $\mathrm{Abcc6}^{-/-}$mice was higher by factor 2.4 compared to WT mice (Fig. 6B).

The Pcsk9 concentration in serum of 6-month-old $A b c c 6^{-1-}$ mice was 67\% higher than in WT mice (Fig. 6C). In line with this, PXE patients also had $41 \%$ higher PCSK9 serum concentrations than healthy controls (Fig. 6D). 


\section{A cholesterol biosynthetic enzymes}

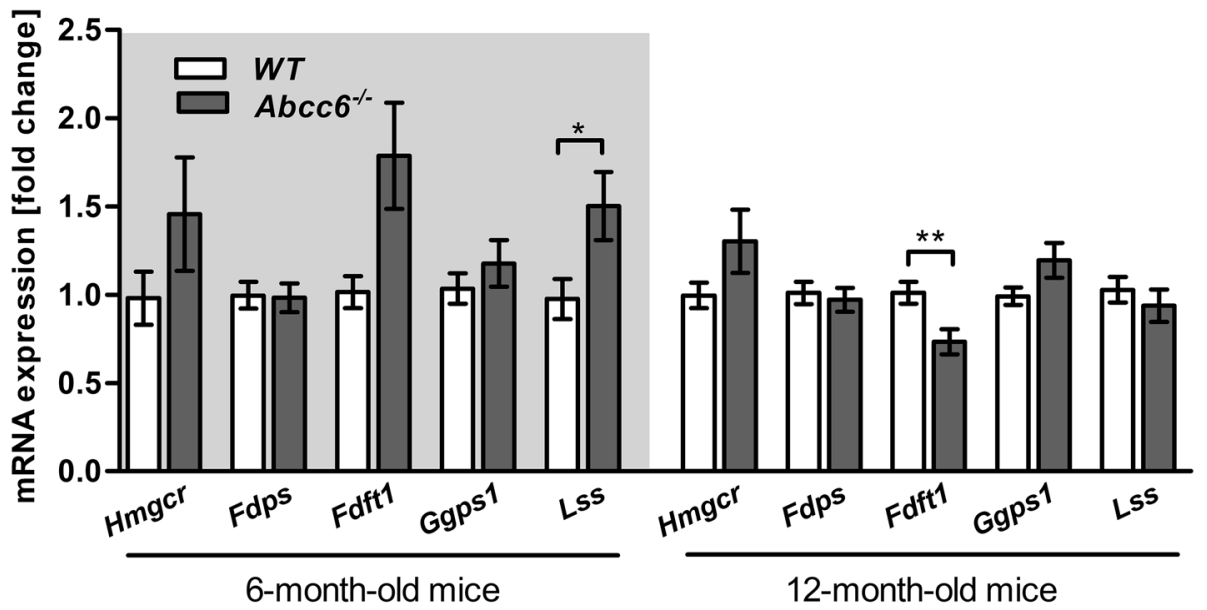

B apolipoproteins

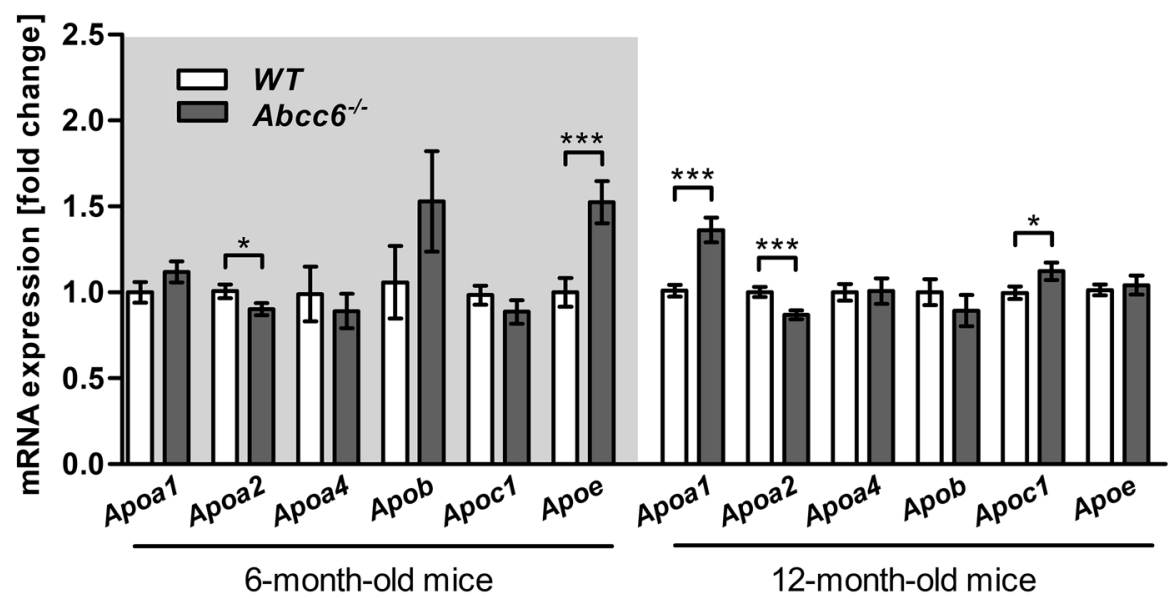

Figure 3. Altered gene expression of cholesterol biosynthetic enzymes and apolipoproteins in Abcc6 knockout mice. (A) Relative hepatic gene expression levels of cholesterol biosynthesis enzymes [3-hydroxy-3methylglutaryl coenzyme A reductase ( $\mathrm{Hmgcr}$ ), farnesyl pyrophosphate synthase ( $\mathrm{Fdps}$ ), farnesyl-diphosphate farnesyltransferase 1 ( Fdft1), geranylgeranyl pyrophosphate synthase 1 (Ggps1) and lanosterol synthase (Lss)] and (B) apolipoproteins (Apoa1, Apoa2, Apoa4, Apob, Apoc1 and Apoe) of WT and Abcc6 ${ }^{-/-}$mice (6-monthold: WT $\mathrm{n}=22, A b c c 6^{-1-} \mathrm{n}=25 ; 12$-month-old: WT $\mathrm{n}=37, A b c c 6^{-1-} \mathrm{n}=39$ ). Data are fold change of mean $\pm \mathrm{SD}$ relative to samples of WT; by Student's $t$ test; ${ }^{*} \mathrm{p} \leq 0.05 ;{ }^{* *} \mathrm{p} \leq 0.01 ;{ }^{* *} \mathrm{p} \leq 0.001$.

\section{Discussion}

Human genetic studies have demonstrated that diverse sequence variations of well-known genes, such as LIPC, $A B C A 1$ or even ABCC6, which cause PXE, are not disease-causing, but associated with decreased HDL cholesterol $^{6,7,20,21}$. This association could be directly related to a higher cardiovascular risk in PXE patients. Studies of human and mice found an increased carotid intima media thickness ${ }^{22-24}$ due to ABCC6 deficiency, which correlates with higher risk for cardiovascular complications ${ }^{25}$. In current case reports it has been noticed that PXE patients suffer from degenerated and calcified elastic fibers in heart tissue as well stenosis in coronary $\operatorname{arteries}^{26,27}$. Furthermore, in a cardiac ischemia-reperfusion injury mice model could be demonstrated that the infarct size in heart tissue was increased in $A b c c 6^{-/-}$mice ${ }^{28}$.

In line with a previous study by Gorgels et al. ${ }^{8}$, which reported lower total and HDL cholesterol in 8-monthold but not in the 2.5-month-old $A b c c 6^{-/-}$mice, we also observed an age-dependent reduction of serum total $(-10 \%)$ and HDL cholesterol (-20\%) in 6-month-old $A b c c 6^{-/-}$mice. These reductions increased with increasing age. Hence, $A b c c 6^{-/-}$mice at an age of 12 months presented lower concentrations of total $(-20 \%)$ and HDL cholesterol $(-25 \%)$. Whereas Guo et al. ${ }^{9}$, showed an increase of total cholesterol and triglyceride levels in 3-month-old $\mathrm{Abcc6}^{-/-}$mice. These similar studies on mice seem to give conflicting results which should be reasoned with different ages of analyzed animals as well with using two distinct $A b c c 6$ knockout models by different gene targeting strategies ${ }^{8,9,29}$. Several studies have demonstrated that a low HDL cholesterol level is a pivotal and independent factor from LDL cholesterol to facilitate coronary heart diseases ${ }^{30}$. The two most important 
A ApoA-I

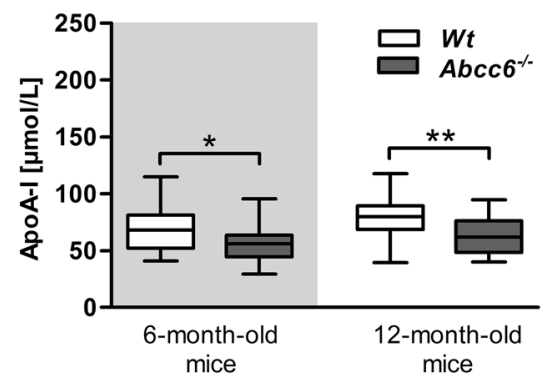

D ApoB

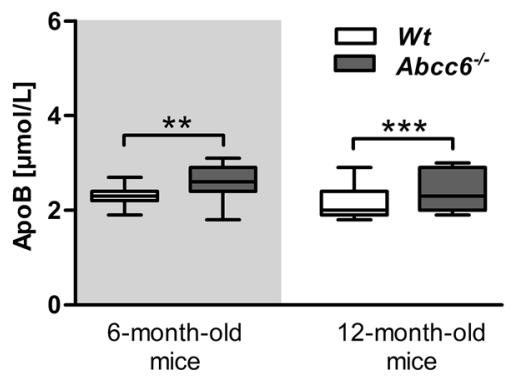

B ApoA-II

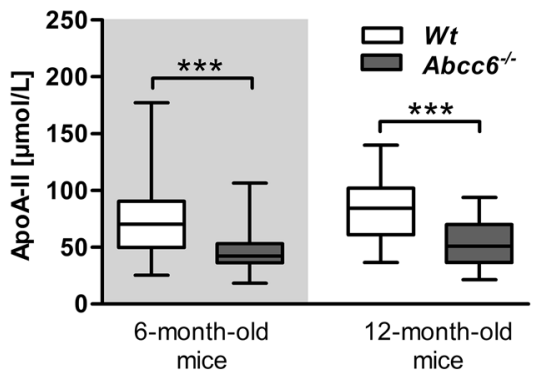

E ApoC-I

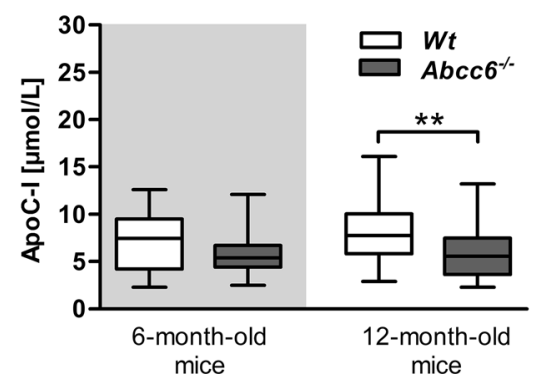

C ApoA-IV

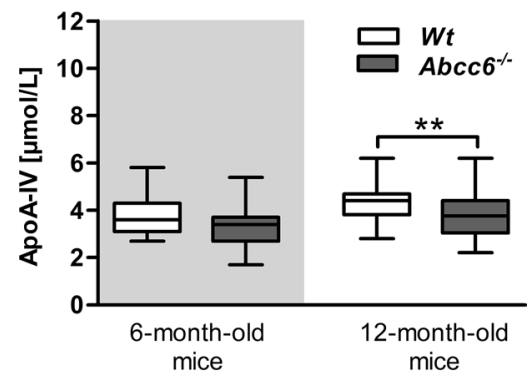

F ApoE

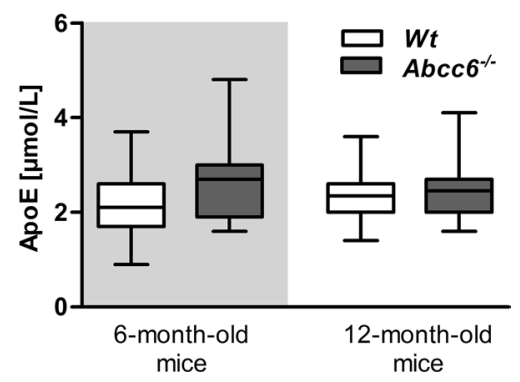

Figure 4. Reduced serum levels of HDL-associated apolipoproteins and elevated ApoB serum levels in Abcc6 knockout mice. Apolipoprotein serum levels of WT and $A b c c 6^{-/-}$mice (6-month-old: WT n $=28, A b c c 6^{-/-}$ $\mathrm{n}=19 ;$;2-month-old: WT n =41, Abcc6-1- $\mathrm{n}=40$ ). (A) ApoA-I, (B) ApoA-II, (C) ApoA-IV, (D) ApoB, (E) ApoC-I and (F) ApoE. Data are mean \pm SD; one factorial variance analysis; ${ }^{*} \mathrm{p} \leq 0.05 ;{ }^{* *} \mathrm{p} \leq 0.01 ;{ }^{* * *} \mathrm{p} \leq 0.001$.

structure elements of HDL particles are ApoA-I and ApoA-I ${ }^{31}$. The ApoA-I protein in conjunction with ABCA1 is responsible for the biogenesis of HDL by serving as a lipid acceptor for excess cholesterol ${ }^{32}$. Another protein ApoC-I regulates activities of various enzymes associated with HDL metabolism. It is responsible for the activation of LCAT and the inhibition of LIPC ${ }^{33}$. Moreover, ApoC-I has an important influence on ApoB-mediated VLDL uptake in the liver. An overexpression of human $A p o C 1$ in a murine model led to a massive increase of serum cholesterol and triglycerides by the accumulation of $\mathrm{VLDL}^{34}$. Unexpectedly, an Apocl knockout in mice was not accompanied by a hypolipidemic phenotype, but rather by normal lipid concentrations in the serum under a normal chow $\operatorname{diet}^{35}$. In this study, we showed for the first time that an Abcc6 deficiency leads to a reduction of ApoA-I, ApoA-II, ApoA-IV and ApoC-I serum concentration in $A b c c 6^{-/-}$mice. This observation might explain the decreased HDL cholesterol level of $A b c c 6^{-/-}$mice and further indicates reduced HDL biogenesis. Another explanation for decreased HDL cholesterol might be altered hepatic expression of Abcal. However, we previously showed that hepatic Abcal expression is not altered in $A b c c 6^{-/-}$mice ${ }^{36}$. A recent study by Dergunov et al. 2020 showed that increased ApoA-I serum levels might be associated with higher ApoA-I release of HDL particles ${ }^{37}$. Released ApoA-I determines the increase of cholesterol efflux of macrophages to circulating HDL. Thus, low level of plasma HDL particles may be compensated by their increased potency for ApoA-I release. The authors suggested ApoA-I release as a new HDL functional property. This is probably not the case in HDL particles in Abcc6-deficient mice suggesting altered HDL functionality. The dysalphalipoproteinemia due to Abcc6-deficiency seen here might lead to a probably decreased flux of cholesteryl ester to the liver and consequently increased hepatic cholesterol synthesis.

In contrast to cholesterol, plant sterols cannot be synthesized by mammalian cells and, thus, must be absorbed with the diet ${ }^{38}$. Serum phytosterol levels, especially of campesterol and $\beta$-sitosterol, reflect intestinal cholesterol absorption $^{38}$ and are furthermore, inversely related to serum precursor concentrations but correlate positively with HDL cholesterol and negatively with cholesterol biosynthesis activity ${ }^{39,40}$. Here, we reported for the first time significantly reduced serum concentrations of esterified and total phytosterols, such as campesterol and $\beta$-sitosterol in both 6- and 12-month-old $A b c c 6^{-/-}$mice. These findings provide a first indication of lower cholesterol and plant sterol absorption due to Abcc6 deficiency. Perhaps the Abcc6 transporter might be partly responsible for functional sterol absorption, as it was demonstrated that the Abcc6 protein is expressed in several parts of the intestine, which are responsible for lipid absorption, particularly for cholesterol uptake $e^{41-43}$. Furthermore, Hosen et al. generated a ranking list for the most likely physiological substrates of ABCC6 by in silico docking analysis. Lipids and bile acids were identified particularly as potential ABCC6 substrates. Thereby, the plant sterol brassicasterol (rank 3), $\beta$-sitosterol as (rank 41) and stigmasterol as (rank 48) were highly ranked ${ }^{5}$.

The ratio of cholesterol precursors to the cholesterol level is used for activity analysis of cholesterol biosynthesis ${ }^{39,44}$. It is notable that the relative concentration of free desmosterol to cholesterol correlates positively with hepatic HMGCR activity, highlighting the rate-limiting step of cholesterol biosynthesis ${ }^{45}$. In addition, cholesterol precursor concentrations in serum are positively related to overall cholesterol biosynthesis and negatively related to cholesterol absorption and HDL cholesterol levels ${ }^{40}$. Here, we describe for the first time that the ratio of $\mathrm{zy} / \mathrm{dh} / 7 \mathrm{dhc}$ to cholesterol was significantly higher by up to $25 \%$ in both age groups of $A b c c 6^{-/-}$mice. 
A lipoprotein metabolizing enzymes

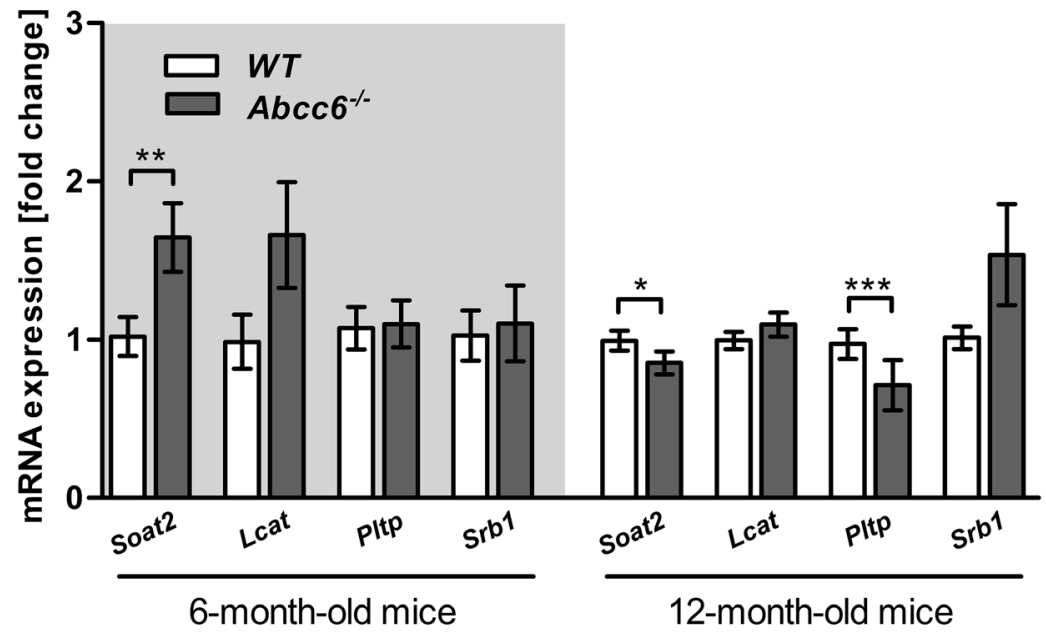

C Lpl \& Lipc gene expression

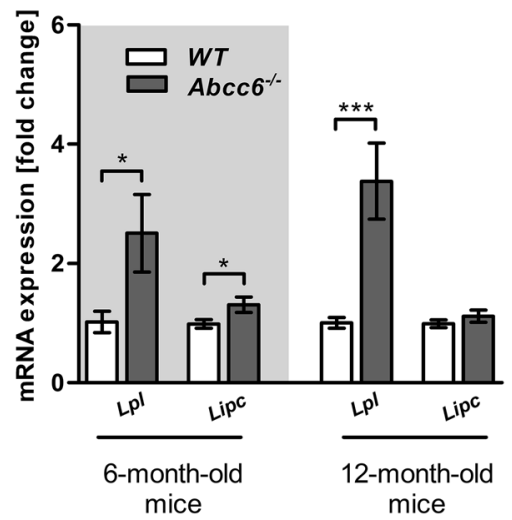

D extrahepatic $L p /$ gene expression

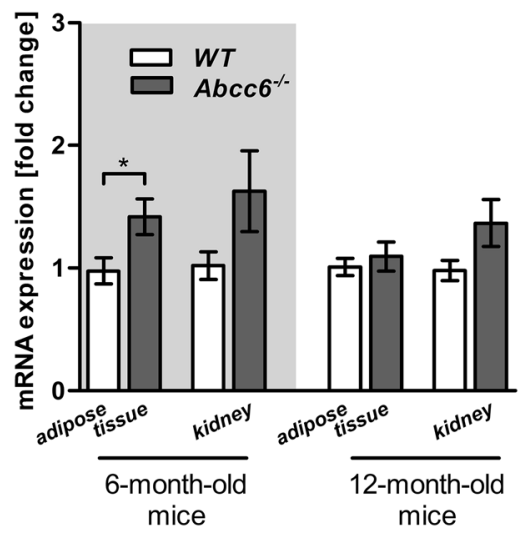

B Lcat activity

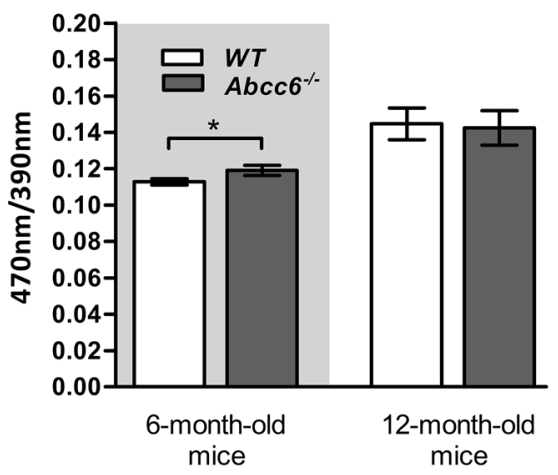

E Lpl serum concentration

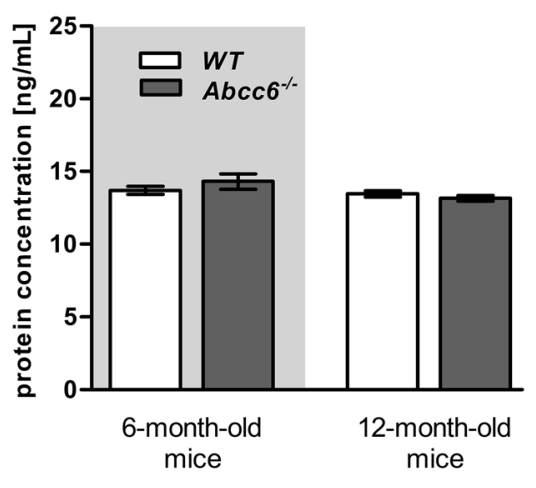

Figure 5. Expression alteration of lipoprotein metabolizing enzymes in Abcc6 knockout mice. (A) Relative hepatic gene expression levels of lipoprotein metabolizing proteins (sterol O-acyltransferase (Soat2), Lcat, phospholipid transfer protein (Pltp) and scavenger receptor B1 (Srb1)) of WT and $A b c c 6^{-/-}$mice (6-monthold: WT $\mathrm{n}=22, A b c c 6^{-/-} \mathrm{n}=25 ; 12$-month-old: WT $\left.\mathrm{n}=37, A b c c 6^{-1-} \mathrm{n}=39\right)$. Data are fold change of mean \pm SD relative to samples of WT. (B) The lecithin-cholesterol acyltransferase (Lcat) activity was determined in serum of WT and $A b c c 6^{-/-}$mice (6-month-old: WT: $\mathrm{n}=22, A b c c 6^{-1-}: \mathrm{n}=15 ; 12$-month-old: WT: $\mathrm{n}=30 A b c c 6^{-/-}: \mathrm{n}=34$ ). Data are mean \pm SD. $(\mathbf{C})$ Relative hepatic gene expression level of lipoprotein lipase $(L p l)$ and hepatic lipase (Lipc) of WT and $A b c c 6^{-/-}$mice (6-month-old: WT n $=22, A b c c 6^{-1-} \mathrm{n}=25 ; 12$-month-old: WT n $=37, A b c c 6^{-1-}$ $\mathrm{n}=39$ ). Data are fold change of mean \pm SD relative to samples of WT. (D) Relative gene expression level of $L p l$ in the kidney and white adipose tissue of WT and $A b c c 6^{-1-}$ mice (6-month-old: WT: adipose tissue $\mathrm{n}=22$, kidney $\mathrm{n}=25, A b c c 6^{-/-}$: adipose tissue $\mathrm{n}=18$, kidney $\mathrm{n}=23 ; 12$-month-old: WT: adipose tissue $\mathrm{n}=33$, kidney $\mathrm{n}=34$, $A b c c 6^{-1-}$ : adipose tissue $\mathrm{n}=38$, kidney $\mathrm{n}=42$ ). Data are fold change of mean \pm SD relative to samples of WT. (E) Quantification of Lpl concentration in serum of WT and $A b c c 6^{-/-}$mice (6-month-old: WT: $\mathrm{n}=23, A b c c 6^{-1-}$ : $\mathrm{n}=21$; 12-month-old: WT: $\mathrm{n}=33 A b c c 6^{-/-}: \mathrm{n}=29$ ). Data are mean $\pm \mathrm{SD}$; Student's $t$ test; ${ }^{*} \mathrm{p} \leq 0.05 ;{ }^{* * *} \mathrm{p} \leq 0.001$.

These data support our hypothesis of an increased cholesterol biosynthesis due to Abcc6 deficiency. However, the ratio of lanosterol to cholesterol was unchanged in 6-month-old $A b c c 6^{-/-}$mice and significantly reduced in 12-month-old $A b c c 6^{-/-}$mice. The precursor molecule lanosterol is able to induce the degradation of HMGCR $\operatorname{protein}^{46}$, thus, reduced lanosterol levels will further trigger cholesterol synthesis. We demonstrated in previous cell culture experiments that dermal fibroblasts from PXE patients have a significantly higher HMGCR mRNA expression and activity than healthy control cells ${ }^{11}$. Furthermore, Guo et al. observed in a previous study that a high dose atorvastatin treatment, a competitive HMGCR inhibitor, of $A b c c 6^{-/-}$mice has a preventive effect on vibrissae calcification ${ }^{9}$. Statins may be able to reduce protein prenylation of $\mathrm{G}$ protein RhoA by the inhibition of HMGCR and related metabolic pathways, which activated the bone morphogenetic protein 2 (BMP2) signaling and, therefore, mineralization facilitates ${ }^{10}$. Furthermore, Hosen et al. found that BMP2 signaling in $A b c c 6^{-/-}$mice are active at calcified sites, such as vibrissae and eyes. It was also demonstrated that this signaling pathway is upregulated in human fibroblasts from PXE patients in vitro ${ }^{47}$.

We described here for the first time that Abcc6 deficiency in mice is linked to lower plant sterol and apolipoprotein levels and postulate a disturbed sterol absorption and HDL metabolism. Whereas Abcg5/Abcg8 own there physiological function in the biliary efflux of cholesterol metabolites, we propose a physiological function 


\section{A Pcsk9 \& Ldlr gene expression}

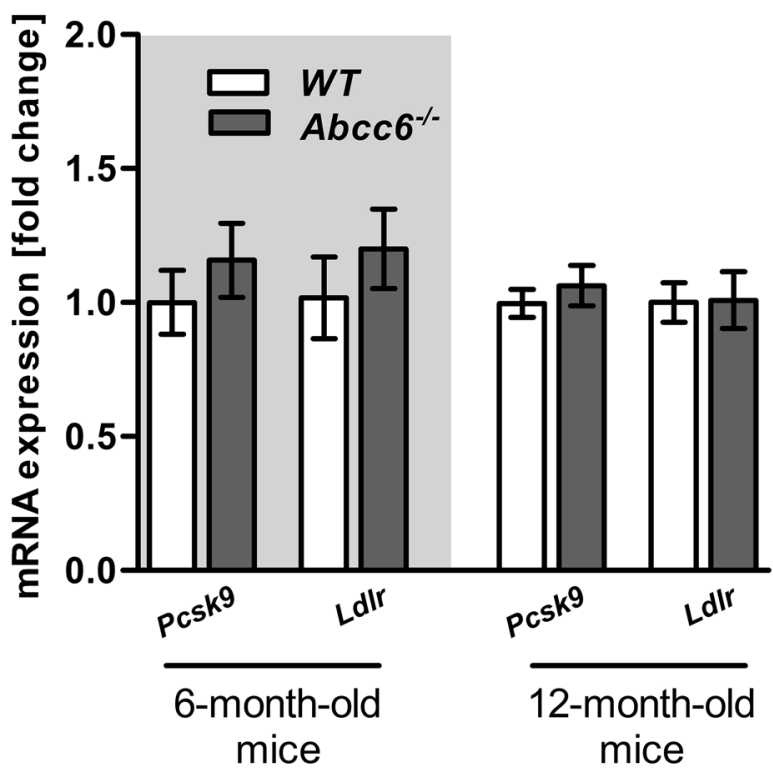

C murine Pcsk9 serum level

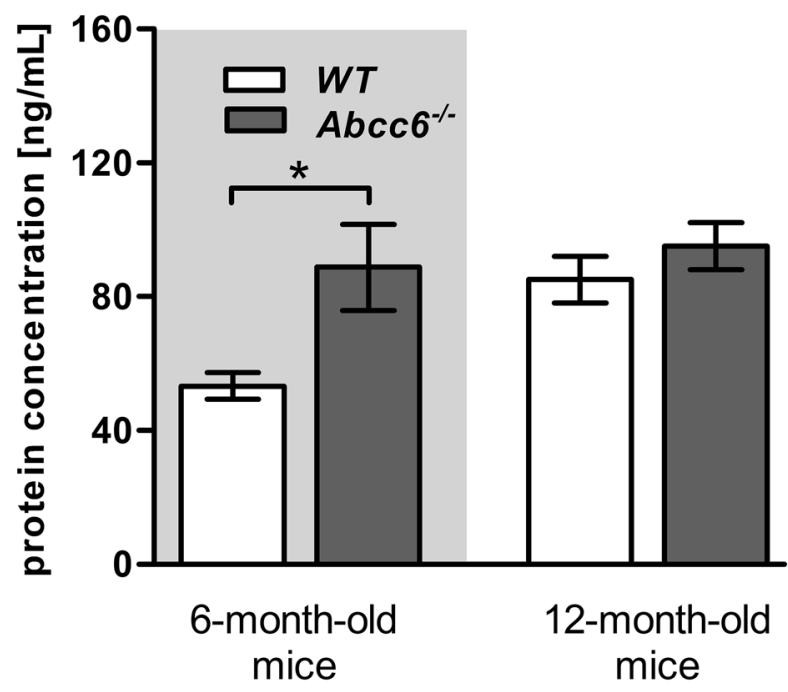

B extrahepatic Lolr gene expression

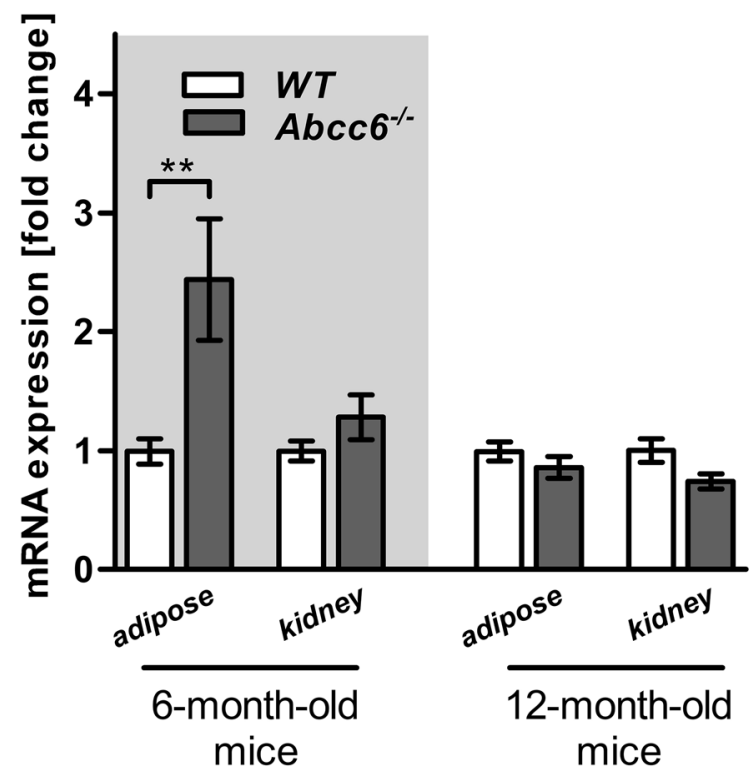

D human PCSK9 serum level

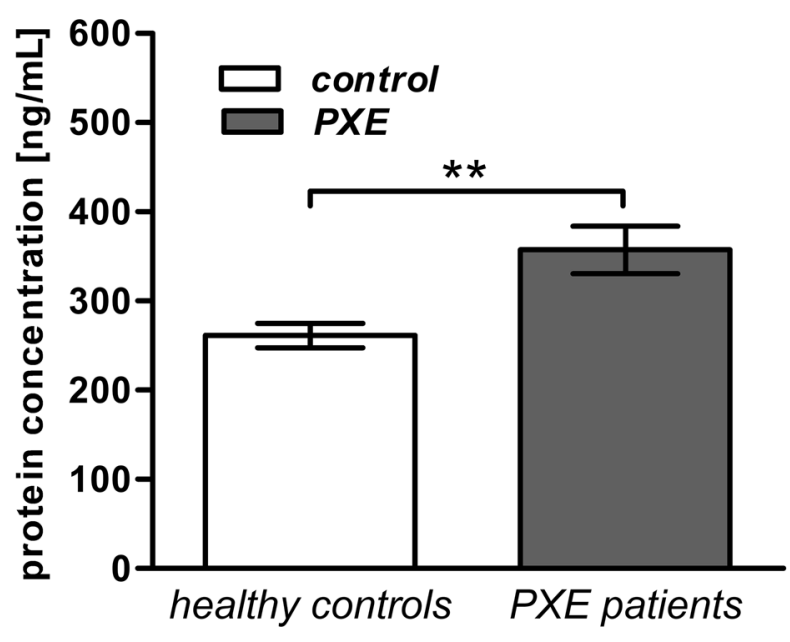

Figure 6. Altered gene and protein expression analysis of proprotein convertase subtilisin/kexin type 9 (Pcsk9) and low-density lipoprotein receptor (Ldlr) in Abcc6 knockout mice and PXE patients. (A) Relative hepatic gene expression level of proprotein convertase subtilisin/kexin type 9 (Pcsk9) and LDL receptor (Ldlr) of WT and $A b c c 6^{-/-}$mice (6-month-old: WT n $=22, A b c c 6^{-/-} \mathrm{n}=25 ; 12$-month-old: WT $\mathrm{n}=37, A b c c 6^{-/-} \mathrm{n}=39$ ). Data are fold change of mean \pm SD relative to samples of WT. (B) Relative gene expression level of $L d l r$ in the kidney and white adipose tissue of WT and $A b c c 6^{-/-}$mice (6-month-old: WT: adipose tissue $\mathrm{n}=22$, kidney $\mathrm{n}=25, A b c c 6^{-/-}$: adipose tissue $\mathrm{n}=18$, kidney $\mathrm{n}=23$; 12 -month-old: $\mathrm{WT}$ : adipose tissue $\mathrm{n}=33$, kidney $\mathrm{n}=34, A b c c 6^{-1-}$ : adipose tissue $n=38$, kidney $n=42$ ). Data are fold change of mean \pm SD relative to samples of WT. $(\mathbf{C})$ Quantification of Pcsk9 concentration in serum of WT and $A b c c 6^{-/-}$mice (6-month-old: WT: $\mathrm{n}=27, A b c c 6^{-/-}: \mathrm{n}=21 ; 12$-monthold: WT: $\mathrm{n}=35 A b c c 6^{-/-}: \mathrm{n}=31$ ). Data are mean \pm SD. (D) Quantification of PCSK9 concentration in serum of healthy controls and PXE patients (healthy controls: $n=36$, PXE patients: $n=36$ ). Data are mean \pm SD; Student's $t$ test; ${ }^{*} \mathrm{p} \leq 0.05 ;{ }^{* *} \mathrm{p} \leq 0.01$. 

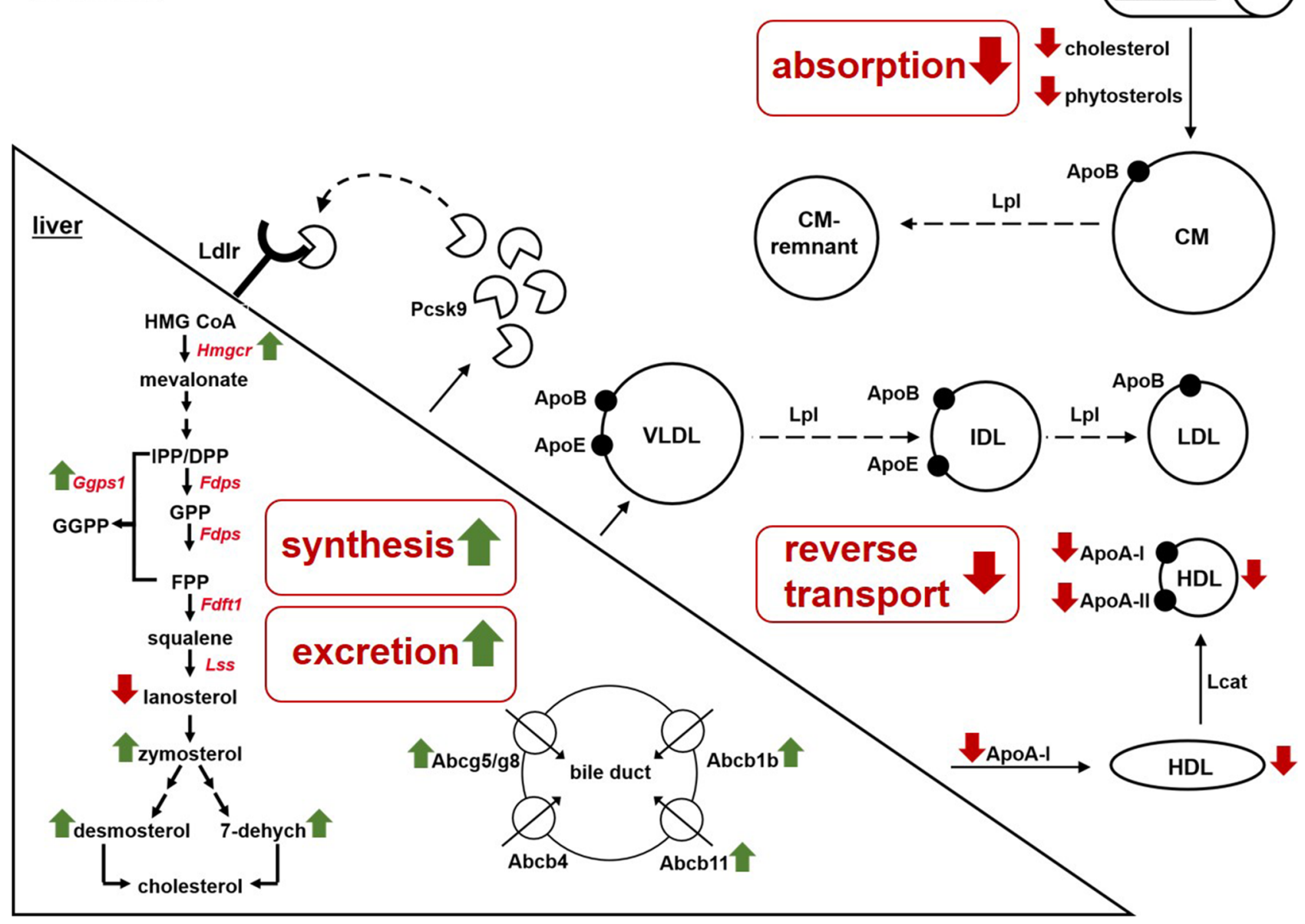

Figure 7. Hypothetic model of Abcc6 function in cholesterol homeostasis of mice. This model summarizes the results obtained in this study and illustrates the possible effects of an Abcc6 loss of function in maintaining cholesterol homeostasis in mice. We further demonstrated a disturbed reverse cholesterol transport by reduction of important apolipoproteins for HDL functionality in serum of $A b c c 6^{-/-}$mice (ApoA-I and ApoA-II). We found elevated cholesterol precursors in serum of Abcc6 knockout mice (zymosterol, desmosterol, 7-dehydrocholesterol) as hint for an increased overall cholesterol synthesis. In a former study, we showed that $\mathrm{Abcg} 5 / \mathrm{Abcg} 8$ expression in the liver of $A b c c 6^{-/-}$mice was induced, suggesting an increased sterol excretion by the liver ${ }^{50}$. In summary, we propose that Abcc6-deficiency in mice might be accompanied by a reduced absorption of cholesterol and thereby phytosterols in the intestine. Green arrows indicate increased target expression, increased protein/metabolite concentration or activation of a pathway, red arrows indicate the repression of target expression or protein/metabolite concentration or inactivation of a pathway. See text for further details. CM chylomicron, Lpl lipoprotein lipase, Pcsk9 proprotein convertase subtilisin/ kexin type 9, $L d l r$ LDL receptor, IDL intermediate density lipoprotein, Abc ABC-transporter, Fdps farnesyl pyrophosphate synthase, Fdft1 farnesyl diphosphate farnesyl transferase 1, Ggps 1 geranylgeranyl pyrophosphate synthase 1, Lss lanosterol synthase, IPP/DPP isopentenyl pyrophosphate/dimethyallyl pyrophosphate, GPP geranyl pyrophosphate, GGPP geranylgeranyl pyrophosphate, FPP farnesyl pyrophosphate, 7-dehydroch 7-dehydrocholesterol.

cholesterol homeostasis and indicate impaired cholesterol metabolism as an important pathomechanism involved in PXE manifestation (summarized in Fig. 7). These findings raise new questions about how cholesterol and lipid metabolism are regulated due to Abcc6 deficiency. Further studies are definitely necessary to understand the complex gene regulatory network and tissue specificity regulating cholesterol metabolism due to ABCC6 deficiency.

\section{Materials and methods}

All experiments within this study were performed in accordance with relevant guidelines and regulations.

Animals. All experiments within this study were performed using dead animals. Mice were killed solely for the use of their organs or tissues without incriminating experiments. Therefore, animal preparations comply with the law on animal welfare of Germany used for scientific purposes, an ethical approval for our study 
was not required. The $A b c c 6^{-/-}$mice were generated on a hybrid background of C57BL/6 and 129/Ola and were backcrossed to C57BL/6 for more than 5 generations ${ }^{8}$. Mice were housed under standard conditions in a pathogen-free central animal facility of Bielefeld University (Germany) and kept with water and food (normal chow) ad libitum and therefore non-fasted blood samples were used for lipid analysis. In the present study, we used $A b c c 6(+/+)$ littermates and pure C57BL/6 mice as WT control mice. Mice (males and females), aged 6 months \pm 2 weeks and 12 months \pm 4 weeks, were anesthetized intraperitoneal with $0.65 \mathrm{mg}$ ketamine, $0.02 \mathrm{mg}$ acepromazine and $0.13 \mathrm{mg}$ xylazine per $10 \mathrm{~g}$ bodyweight and sacrificed by bleeding subsequent to cervical dislocation. After opening the thorax, the right ventricle of the heart was cut for liver perfusion via the hepatic portal vein with PBS. Liver, kidneys and perigonadal white adipose tissue were collected, immediately frozen in liquid $\mathrm{N}_{2}$ and stored at $-80^{\circ} \mathrm{C}$ until use. Serum was obtained by centrifugation of the blood samples collected at $3000 \mathrm{~g}$ for $10 \mathrm{~min}$ at room temperature. Serum was stored at $-80^{\circ} \mathrm{C}$ until use $\mathrm{s}^{36}$.

Patient characteristics. The diagnosis of PXE in all patients was consistent with the consensus criteria reported. Eleven male [mean \pm SD age, $47.8 \pm 5.5$ years] and 25 female [38.7 \pm 11.4 years] PXE patients, and 11 male [ $47.8 \pm 5.5$ years] and 25 female [ $38.7 \pm 11.4$ years] blood donors were included in this study as healthy controls. All patients and controls gave their written informed consent for participation in the study. The study was conducted in accordance with the Declaration of Helsinki and approved by the ethics Committee of the HDZ NRW, Department of Medicine, Ruhr University of Bochum (registry no. 32/08). Selected lipid parameters were measured and are shown in Supplementary Table 2.

Serum levels of mouse pre-heparin Lpl. The concentration of pre-heparin Lpl in serum was measured via a commercial enzyme-linked immunosorbent assay Mouse LPL ELISA Kit (Biozol Diagnostica GmbH, Eching, Germany), according to the manufacturer's protocol. Samples were diluted 1:20.

Serum levels of human and mouse PCSK9. Serum levels of PCSK9 were measured using the Human PCSK9 Quantikine ELISA Kit or Mouse PCSK9 Quantikine ELISA Kit (R\&D Systems, Inc., Minneapolis, MN, USA), according to the manufacturer's instructions. Human serum was diluted 1:20 and murine serum 1:200.

Quantification of HDL and LDL/VLDL cholesterol. The HDL and LDL/VLDL cholesterol levels of serum were measured using an HDL and LDL/VLDL Quantification Colorimetic/Fluorometic Kit (BioVision Incorporated, Milpitas, USA), according to the manufacturer's instructions. After precipitation, $10 \mu \mathrm{L}$ of the $\mathrm{HDL}$ and $20 \mu \mathrm{L}$ of the LDL/VLDL suspension were used for photometric quantification.

Quantification of oxLDL cholesterol. The oxLDL cholesterol levels of serum were determined by a commercial Mouse oxLDL ELISA Kit (Cloud-Clone Corp., Houston, USA), according to the manufacturer's instructions. Samples were diluted 1:100.

Lcat activity assay. The Lcat activity in serum was determined by using a commercial LCAT assay kit (Sigma-Aldrich, Taufkirchen, Germany; supplied by Roar Biomedical, Inc., New York, NY) according to the manufacturer's protocol. An amount of $2 \mu \mathrm{L}$ of undiluted serum were incubated with the intact substrate for $6 \mathrm{~h}$ at $37^{\circ} \mathrm{C}$.

RNA extraction from tissue, cDNA synthesis and Quantitative Real-Time PCR. Total RNAs were extracted from $100 \mathrm{mg}$ liver using QIAzol reagent (Qiagen, Hilden, Germany), followed by a purification using RNeasy Mini protocol (Qiagen, Hilden, Germany). Total RNA was treated with DNase I (Macherey-Nagel $\mathrm{GmbH} \& \mathrm{Co}$. KG, Bottrop, Germany) on mini-columns to eliminate genomic DNA. The RNA quantification was assessed by using the NanoDrop 2000 spectrophotometer (Thermo Fisher, Schwerte, Germany) and RNA quality was determined using the Agilent RNA 6000 Nano Kit (Agilent Technologies, Ratingen, Germany), according to the manufacturer's instructions. First-strand cDNA was synthesized from $1 \mu \mathrm{g}$ of total RNA for each reaction using the SuperScript II Reverse Transcriptase Kit (Thermo Fisher, Schwerte, Germany), according to the manufacturer's instructions. The cDNA was diluted 1:5 or 1:10 with water, depending on the target gene, and stored at $-20^{\circ} \mathrm{C}$ prior to quantitative real-time PCR (qRT-PCR). The qRT-PCR was performed on a LightCycler480 (Roche, Mannheim, Germany) using Lightcycler480 MasterCycler SYBR Green (Roche, Mannheim, Germany) to assess the mRNA expression levels of target and reference genes. All intron-spanning primers used for qRT-PCR analysis were designed with Clone Manager Suite 7 (Scientific \& Educational Software), synthesized by Biomers (Ulm, Germany) and are listed in the Supplementary Table 1. The PCR thermal cycling conditions contained an initial incubation of $5 \mathrm{~min}$ at $95^{\circ} \mathrm{C}$, followed by 45 cycles of $10 \mathrm{~s}$ denaturation at $95^{\circ} \mathrm{C}$, primer-specific annealing for $15 \mathrm{~s}$ at $65^{\circ} \mathrm{C}$ or $59^{\circ} \mathrm{C}$, and $20 \mathrm{~s}$ elongation and detection of the amplicon at $72^{\circ} \mathrm{C}$. Finally, a melting curve analysis of the amplicon was performed. Each cDNA sample was run in technical triplicates. Water was used as a negative control for each primer pair. The relative amount of target mRNA in each sample was calculated using the $\Delta \Delta \mathrm{Ct}$ method, as previously described ${ }^{48}$. Relative mRNA expression levels were corrected by PCR efficiency and the reference genes normalization factor, by normalizing target mRNA Ct values to those of glyceraldehyde-3-phosphate dehydrogenase (Gapdh), hypoxanthine phosphor-ribosyltransferase 1 (Hprt) and beta-2 microglobulin $(\beta 2 m)$ (6-month-old mice) or Gapdh, Hprt and eukaryotic translation initiation factor 3 subunit A (Eif3a) (12-month-old mice). A cutoff for no detectable mRNA expression was set to a Ct value of $35^{36}$. 
Quantification of apos. Murine serum apos A-I, A-II, A-IV, B, C-I and E were quantified via tryptic proteotypic peptides applying liquid chromatography coupled to tandem mass spectrometry (LC-MS/MS). Method parameters including sample preparation were adapted from a standardized targeted proteomics assay for human apos ${ }^{49}$.

Quantification of free and esterified sterols. Quantification of free and esterified cholesterol, cholesterol precursors, such as free lanosterol and free zymosterol/desmosterol/7-dehydrocholesterol (zy/de/7dhc), and phytosterols, such as brassicasterol, campesterol, $\beta$-sitosterol, and stigmasterol $(\mathrm{mg} / \mathrm{mL})$, were determined as published ${ }^{50,51}$.

Statistical analysis. Data are presented as means with corresponding standard error of the means (SD). Graphic data processing and statistical analysis were performed with GraphPad Prism 5 (GraphPad Software, Inc., CA, USA), using Student's $t$ tests for two group comparisons (two-tailed) and the non-parametric MannWhitney $U$ test for data which are not Gaussian distributed. Data were checked for normality using the Shapiro-Wilk test. From inhomogeneous variations a correction of the t-value according to Welch was carried out. In case of more than two groups the comparisons were analyzed using single factor variance analysis with Bonferroni correction. Statistical significance was accepted at $\mathrm{p} \leq 0.05$.

Received: 20 November 2019; Accepted: 22 December 2020

Published online: 22 January 2021

\section{References}

1. Germain, D. P. Pseudoxanthoma elasticum. Orphanet J. Rare Dis. 12, 85 (2017).

2. Zak, A., Zeman, M., Slaby, A. \& Vecka, M. Xanthomas: Clinical and pathophysiological relations. Biomedical Papers of the Medical Faculty of Palacky University in Olomouc 158 (2014).

3. Ziegler, S. G. et al. Ectopic calcification in pseudoxanthoma elasticum responds to inhibition of tissue-nonspecific alkaline phosphatase. Sci. Transl. Med. 9, eaal1669 (2017).

4. Borst, P., Váradi, A. \& van de Wetering, K. PXE, a mysterious inborn error clarified. Trends Biochem. Sci. 44, 125-140 (2019).

5. Hosen, M. J. et al. Molecular docking simulations provide insights in the substrate binding sites and possible substrates of the ABCC6 transporter. PLoS ONE 9, e102779 (2014).

6. Wang, J., Near, S., Young, K., Connelly, P. W. \& Hegele, R. A. ABCC6 gene polymorphism associated with variation in plasma lipoproteins. J. Hum. Genet. 46, 699-705 (2001).

7. Peloso, G. M. et al. Common genetic variation in multiple metabolic pathways influences susceptibility to low HDL-cholesterol and coronary heart disease. J. Lipid Res. 51, 3524-3532 (2010).

8. Gorgels, T. G. M. F. et al. Disruption of Abcc6 in the mouse: Novel insight in the pathogenesis of pseudoxanthoma elasticum. Hum. Mol. Genet. 14, 1763-1773 (2005).

9. Guo, H., Li, Q., Chou, D. W. \& Uitto, J. Atorvastatin counteracts aberrant soft tissue mineralization in a mouse model of pseudoxanthoma elasticum $\left(\right.$ Abcc6 $\left.^{-1-}\right)$. J. Mol. Med. 91, 1177-1184 (2013).

10. Luft, F. C. Pseudoxanthoma elasticum and statin prophylaxis. J. Mol. Med. 91, 1129-1130 (2013).

11. Kuzaj, P. et al. ABCC6-a new player in cellular cholesterol and lipoprotein metabolism?. Lipids Health Dis. 13, 118 (2014).

12. Jansen, R. S. et al. ABCC6 prevents ectopic mineralization seen in pseudoxanthoma elasticum by inducing cellular nucleotide release. Proc. Natl. Acad. Sci. 110, 20206-20211 (2013).

13. Li, Q., van de Wetering, K. \& Uitto, J. Pseudoxanthoma elasticum as a paradigm of heritable ectopic mineralization disorders: Pathomechanisms and treatment development. Am. J. Pathol. 189, 216-225 (2018).

14. Bäck, M. et al. Endogenous calcification inhibitors in the prevention of vascular calcification: A consensus statement from the COST action EuroSoftCalcNet. Front. Cardiovasc. Med. 5, 196 (2018)

15. Vaisman, D. N., McCarthy, A. D. \& Cortizo, A. M. Bone-specific alkaline phosphatase activity is inhibited by bisphosphonates. Biol. Trace Elem. Res. 104, 131-140 (2005).

16. Russell, R. G. G. Bisphosphonates: The first 40 years. Bone 49, 2-19 (2011).

17. Ramasamy, I. Recent advances in physiological lipoprotein metabolism. Clin. Chem. Lab. Med. (CCLM) 52, 1695-1727 (2014).

18. Kiss, R. S. \& Sniderman, A. Shunts, channels and lipoprotein endosomal traffic: A new model of cholesterol homeostasis in the hepatocyte. J. Biomed. Res. 31, 95 (2017).

19. Dietschy, J. M., Turley, S. D. \& Spady, D. K. Role of liver in the maintenance of cholesterol and low density lipoprotein homeostasis in different animal species, including humans. J. Lipid Res. 34, 1637-1659 (1993).

20. Trip, M. D. et al. Frequent mutation in the ABCC6 gene (R1141X) is associated with a strong increase in the prevalence of coronary artery disease. Circulation 106, 773-775 (2002).

21. Pisciotta, L. et al. Pseudoxanthoma elasticum and familial hypercholesterolemia: A deleterious combination of cardiovascular risk factors. Atherosclerosis 210, 173-176 (2010).

22. Germain, D. P., Boutouyrie, P., Laloux, B. \& Laurent, S. Arterial remodeling and stiffness in patients with pseudoxanthoma elasticum. Arterioscler. Thromb. Vasc. Biol. 23, 836-841 (2003).

23. Kornet, L. et al. In patients with pseudoxanthoma elasticum a thicker and more elastic carotid artery is associated with elastin fragmentation and proteoglycans accumulation. Ultrasound Med. Biol. 30, 1041-1048 (2004).

24. Kupetsky-Rincon, E. A., Li, Q. \& Uitto, J. Magnesium reduces carotid intima-media thickness in a mouse model of pseudoxanthoma elasticum: A novel treatment biomarker. Clin. Transl. Sci. 5, 259-264 (2012).

25. Lefthériotis, G. et al. The vascular phenotype in Pseudoxanthomaelasticum and related disorders: Contribution of a genetic disease to the understanding of vascular calcification. Front. Genet. 4, 4 (2013).

26. Vos, A. et al. The amount of calcifications in pseudoxanthoma elasticum patients is underestimated in computed tomographic imaging; A post-mortem correlation of histological and computed tomographic findings in two cases. Insights Imaging $\mathbf{9}, 493-498$ (2018).

27. Anzai, F. et al. Successful revascularization of advanced coronary artery disease associated with pseudoxanthoma elasticum. $J$. Cardiol. Cases 16, 101-104 (2017).

28. Mungrue, I. N. et al. Abcc6 deficiency causes increased infarct size and apoptosis in a mouse cardiac ischemia-reperfusion model. Arterioscler. Thromb. Vasc. Biol. 31, 2806-2812 (2011). 
29. Klement, J. F. et al. Targeted ablation of the abcc6 gene results in ectopic mineralization of connective tissues. Mol. Cell. Biol. 25, 8299-8310 (2005).

30. Wilson, P. W. High-density lipoprotein, low-density lipoprotein and coronary artery disease. Am. J. Cardiol. 66, A7-A10 (1990).

31. Duriez, P. \& Fruchart, J. High-density lipoprotein subclasses and apolipoprotein AI. Clin. Chim. Acta 286, 97-114 (1999).

32. Wang, S. \& Smith, J. D. ABCA1 and nascent HDL biogenesis. BioFactors 40, 547-554 (2014).

33. Von Eckardstein, A. \& Kardassis, D. High Density Lipoproteins: From Biological Understanding to Clinical Exploitation Vol. 224 (Springer, Berlin, 2014).

34. Shachter, N. S. et al. Combined hyperlipidemia in transgenic mice overexpressing human apolipoprotein Cl. J. Clin. Investig. 98, 846-855 (1996).

35. Van Ree, J. et al. Increased response to cholesterol feeding in apolipoprotein C1-deficient mice. Biochem. J. 305, 905 (1995).

36. Ibold, B. et al. Abcc6 deficiency in mice leads to altered ABC transporter gene expression in metabolic active tissues. Lipids Health Dis. 18, 2 (2019).

37. Dergunov, A. et al. Denaturation of human plasma high-density lipoproteins by urea studied by apolipoprotein A-I dissociation. Biochim. Biophys Acta Mol. Cell Biol. Lipids 1866(1), 158814 (2020).

38. Vanmierlo, T. et al. Dietary intake of plant sterols stably increases plant sterol levels in the murine brain. J. Lipid Res. 53, 726-735 (2012).

39. Miettinen, T. A., Tilvis, R. S. \& Kesäniemi, Y. A. Serum plant sterols and cholesterol precursors reflect cholesterol absorption and synthesis in volunteers of a randomly selected male population. Am. J. Epidemiol. 131, 20-31 (1990).

40. Gylling, H. \& Miettinen, T. A. Serum noncholesterol sterols related to cholesterol metabolism in familial hypercholesterolemia. Clin. Chim. Acta 178, 41-49 (1988).

41. Beck, K. et al. The distribution of Abcc6 in normal mouse tissues suggests multiple functions for this ABC transporter. J. Histochem. Cytochem. 51, 887-902 (2003).

42. Taipalensuu, J. et al. Correlation of gene expression of ten drug efflux proteins of the ATP-binding cassette transporter family in normal human jejunum and in human intestinal epithelial Caco-2 cell monolayers. J. Pharmacol. Exp. Ther. 299, 164-170 (2001).

43. Mutch, D. M. et al. Regional variations in ABC transporter expression along the mouse intestinal tract. Physiol. Genomics 17, 11-20 (2004).

44. Matthan, N. R., Raeini-Sarjaz, M., Lichtenstein, A. H., Ausman, L. M. \& Jones, P. J. Deuterium uptake and plasma cholesterol precursor levels correspond as methods for measurement of endogenous cholesterol synthesis in hypercholesterolemic women. Lipids 35, 1037-1044 (2000).

45. Björkhem, I. et al. Correlation between serum levels of some cholesterol precursors and activity of HMG-CoA reductase in human liver. J. Lipid Res. 28, 1137-1143 (1987)

46. Nguyen, A. D., McDonald, J. G., Bruick, R. K. \& DeBose-Boyd, R. A. Hypoxia stimulates degradation of 3-hydroxy-3-methylglutaryl-coenzyme A reductase through accumulation of lanosterol and hypoxia-inducible factor-mediated induction of insigs. $J$. Biol. Chem. 282, 27436-27446 (2007).

47. Hosen, M. J., Coucke, P. J., Le Saux, O., De Paepe, A. \& Vanakker, O. M. Perturbation of specific pro-mineralizing signalling pathways in human and murine pseudoxanthoma elasticum. Orphanet J. Rare Dis. 9, 66 (2014).

48. Livak, K. J. \& Schmittgen, T. D. Analysis of relative gene expression data using real-time quantitative PCR and the 2(-Delta Delta $\mathrm{C}(\mathrm{T})$ ) method. Methods 25, 402-408 (2001).

49. Ceglarek, U. et al. Quantification of seven apolipoproteins in human plasma by proteotypic peptides using fast LC-MS/MS. PROTEOMICS-Clin. Appl. 7, 794-801 (2013).

50. Lembcke, J. et al. Rapid quantification of free and esterified phytosterols in human serum using APPI-LC-MS/MS. J. Lipid Res. 46, 21-26 (2005).

51. Becker, S. et al. LC-MS/MS-based quantification of cholesterol and related metabolites in dried blood for the screening of inborn errors of sterol metabolism. Anal. Bioanal. Chem. 407, 5227-5233 (2015).

\section{Acknowledgements}

We thank Axel Ziesenis for his excellent advice on mouse care and management. We further thank Friedrich Krüger, Christoph Lichtenberg, René Kottkamp, Leonie Schröder and Babette Zögner for their excellent technical assistance and Philip Saunders for his linguistic advice. For enquiries about this publication please contact Doris Hendig at dhendig@hdz-nrw.de or doris.hendig@ruhr-uni-bochum.de.

\section{Author contributions}

B.I. performed experiments, analyzed the data, draw the figures and wrote the manuscript. U.C. and J.D. performed the mass spectrometric analysis of sterols and apolipoproteins. J.T. and I.F. contributed to the data analysis and manuscript revision. T.G., A.B., O.V., M.G. and U.C. supported the study and experimental design and revised the manuscript critically. D.H. and C.K. initiated the study, designed the experiments, supervised the project and contributed to the drawing of figures and writing of the manuscript.

\section{Funding}

Open Access funding enabled and organized by Projekt DEAL. We acknowledge support by the Open Access Publication Funds of the Ruhr-Universität Bochum.

\section{Competing interests}

The authors declare no competing interests.

\section{Additional information}

Supplementary Information The online version contains supplementary material available at https://doi. org/10.1038/s41598-021-81573-1.

Correspondence and requests for materials should be addressed to D.H.

Reprints and permissions information is available at www.nature.com/reprints.

Publisher's note Springer Nature remains neutral with regard to jurisdictional claims in published maps and institutional affiliations. 
(c) (i) Open Access This article is licensed under a Creative Commons Attribution 4.0 International cc) License, which permits use, sharing, adaptation, distribution and reproduction in any medium or format, as long as you give appropriate credit to the original author(s) and the source, provide a link to the Creative Commons licence, and indicate if changes were made. The images or other third party material in this article are included in the article's Creative Commons licence, unless indicated otherwise in a credit line to the material. If material is not included in the article's Creative Commons licence and your intended use is not permitted by statutory regulation or exceeds the permitted use, you will need to obtain permission directly from the copyright holder. To view a copy of this licence, visit http://creativecommons.org/licenses/by/4.0/.

(C) The Author(s) 2021 